\title{
Your Asia-Pacific Network: The use of Radio Australia by the Australian Government
}

\section{ABSIRACI}

This article examines the use of Radio Australia by the Australian Government. It examines the extent that the Australian Government's foreign policy goals are reflected in the charter and programming of Radio Australia. The paper begins with a brief historical look at Radio Australia followed by description and analysis of the role of government control in Radio Australia's operation; the role of an intermediary between the government and the station, which, in this case, is the Australian Broadcasting Corporation (ABC), the parent company of Radio Australia; the programme philosophy of, and programming offered by Radio Australia, and criticisms of Radio Australia from within the Pacific.

\author{
ANDREW M. CLARK \\ The University of Texas
}

R ADIO AUSTRALIA is one of the oldest Government-owned international

Roadcast stations in the world. At times it has enjoyed strong support from the Government, while at other times it has come perilously close to being shut down.

\section{Radio Australia history}

Radio Australia began shortwave broadcasting in 1939 after a request from the British for help in countering propaganda being disseminated by the Germans. The Australian government agreed to the request but could not decide who 
should control the new service. Eventually, several Government agencies cooperated: The Department of Information would prepare the content of the programs; the Australian Broadcasting Corporation (ABC) would provide thebroadcast personnel and translation services to present the programmes, and the Postmaster-General's Department, would take care of technical matters (Thomas, 1980). The service officially began broadcasting on 20 December 20 1939. Prime Minister Menzies opened the station noting,

Our reasons for establishing broadcasts of this kind may be quite simply stated. We have decided that over some of the propaganda stations to which you listen, so many strange things are said, not only about Australia, but about the whole of the British Empire, that the time has come to speak for ourselves.... My purpose is to tell you something about Australia and the war. Something about why it is that although we are 12,000 miles from Europe we are nevertheless involved in a European war and in full partnership with Great Britain and its conduct (as cited in Hodge, 1995: 8).

The broadcasts always began with the sound of the kookaburra, and with broadcasts in English, French, German, Dutch, and Italian. Initial broadcasts focused on parts of Europe, India, South Africa and the Americas.

As is typical of any international station, the languages used, and the areas of the world targeted depended on the priority of the Australian government. These priorities changed according to developments in the war. Disagreement continued throughout the war as to which department was best suited to control the station. The ABC wanted control because it had experienced staff that could put together professionally sounding programmes. In addition, there would be less chance of governmental interference if the $\mathrm{ABC}$ had control. The Department of Information felt the $\mathrm{ABC}$, as a public service broadcaster, would be beholden to the Australian taxpayers who would be unlikely to want to spend money on a service targeting an overseas audience. This would increase the chance the station would be eliminated or given less of a priority than a government department would give it (Thomas, 1980).

By 1941 the ABC was responsible for news broadcasts, but the Department of Information was in charge of all propaganda. The government created another department a year later to coordinate the propaganda war against Japan. The Political Warfare Committee included staff from the Australian Chiefs of Staff, Department of Information, Department of Defense, and External Affairs. 
Thomas (1980) points out that at times it was difficult to know which department was responsible for what task. Unlike many other countries, Australia also used the shortwave medium for internal broadcasts. This meant that listeners in 'enemy countries' (p. 117) could also hear the domestic service of the ABC. This caused problems for those coordinating the propaganda efforts. The director of information at the time Japan entered the war was Charles Holmes. He noted to a colleague that 'it is inevitable that many news bulletins and commentaries which it is perfectly proper and desirable to broadcast to Australians are not all adapted for the presentation of the Australian scene to overseas listeners' (as cited in Hodge, 1995: 20).

In 1942, control of Radio Australia was given to the Australian Broadcasting Corporation, but control of political policy for the station, which amounted to most of the broadcasts, rested with the Department of External Affairs. What little influence the ABC had over Radio Australia ended in 1944 when responsibility for Radio Australia was placed in the hands of the Minister of Information. As has been noted, the Australian Government used Radio Australia during the war as a tool to aid in its war efforts, particularly in Asia. However, Hodge (1995) notes that following the war Radio Australia was used in a new way: 'as an instrument of [the government's] immigration policy' (p. 27). Radio Australia's broadcasts painted an enticing picture of Australia, with its English-language broadcasts designed to attract foreigners to settle in Australia. The British were the primary targets for immigration, but broadcasts in German and Dutch were also framed in a way to attract people to leave behind the turmoil and ruins of Europe and settle in Australia.

By 1950 the administration of Radio Australia shifted from the Ministry of Information back to the Australian Broadcasting Commission. However, a battle over control continued; this time over the model of broadcasting. On the one side were officials in the Department of External Affairs who wanted Radio Australia to model itself after the American system where the international stations were under government control. Those espousing this view saw Radio

Australia solely as a tool of foreign policy and perhaps as one of the most important tools for Australia in the Cold War effort. The Minister of External Affairs in the early 1960s felt the compiling of news should not be left just to journalists and that more attention should be paid to Australia's national interests (Hodge, 1995). On the other side were those from the ABC who favoured the BBC model where the station appeared to have a degree of autonomy andtherefore was less closely tied with government propaganda and 82 PACIFIC JOURNALISM REVIEW 92003 
more with objectivity. This included not just broadcasting the Government's point-of-view, but also criticism of the government by the opposition.

Programme guides from the 1950s and 1960s show Radio Australia programming not only targeted Asia and the Pacific but also targeted Britain, other parts of Europe, and North America. In addition special attention was paid to Australian forces overseas (ABC Online, 2003b, 2003c). In 1967 Radio Australia broadcast 'Forces' News' seven days a week. This 15-minute newscast was described as 'a special bulletin of news with a home-town flavour' (ABC Online, 2003c). 'Forces' News' was followed immediately by 'Forces' Requests' which was described as 'Margaret Wood answers your letters and plays your musical requests as well as passing on messages from sweethearts, families, and friends' (ABC Online, 2003c). These special programmes for Australian military personnel targeted Saigon, Malaysia, Singapore, and Thailand.

Even though Radio Australia is under the auspices of the Australian Broadcasting Corporation, the battle for ideological control of the service has continued. Since the 1970s, whenever there was a crisis, particularly in the Asia/ Pacific region, the demand has been for Radio Australia to revert to an output resembling the American model. In times of relative peace, it seems as if the BBC model has been favored.

Radio Australia continued without major change until the mid 1990s the Australian Government commissioned the Mansfield Report, an independent review conducted by prominent Australian businessman, Robert Mansfield, examining the effectiveness of the Australian Broadcasting Corporation. At the time, the government sought a more focused and effective role for the $\mathrm{ABC}$ (DCITA, 1998). More specifically, the government desired to cut the Australian Broadcasting Corporation's budget, and Radio Australia, with its focus on external audiences, was deemed an area that was expendable.

Recommendation 18 of the Mansfield Report dealt with international broadcasting:

- That the requirement for the $\mathrm{ABC}$ to broadcast programs to audiences outside Australia should cease;

- that the $\mathrm{ABC}$ should retain the ability to transmit programs outside

Australia if it chooses;

- that the $\mathrm{ABC}$ should be permitted to apply net savings from the closure of Radio Australia to the achievement of its savings target-this should include any 
transmission savings, consistent with the Government's commitment to fund the ABC directly for its transmission costs; and

- that if an appropriate commercial arrangement for the operation of Australia Television is not entered into before June 1997, the service should be closed down (DCITA, 1998).

The cutbacks resulting from the report reduced the number of language services offered by Radio Australia from nine to six, and staff from 144 to 66. Transmitters were shut down and then sold off to a religious broadcaster from England. According to Jean-Gabriel Manguy, the Radio Australia network manager, for a while Radio Australia all but disappeared. Manguy reflecting on that period in the station's history noted:

However, there was, from the Government circles in Canberra, the realisation that it was important to maintain at least a Pacific service. So Radio Australia for a while was going to survive with its Pacific service and that includes our English language and Pidgin broadcasts. Then the $\mathrm{ABC}$ Board had a hard look at the situation and felt that although the transmitters to Asia were to be switched off it was still important to keep a production capacity for Asia and a decision was taken to keep some of our Asian language services. And that's what we were left if you want on 1 July 1997 with a Pacific service which was pretty much intact although our own production capacity in English was severely curtailed and a much diminished Asian service, but a service without transmitters. So that was the hard reality of 1 July 1997 (ABC Online, 2002a).

T. R. Rajeesh, a student in India, listened to Radio Australia in India, but the cutbacks meant he had to stop listening to the programs he enjoyed. Rajeesh says, 'Closing down of Darwin transmitters and [programme] reduction due to heavy budgetary cuts in 1996 really caused for the loss of good [programmes] as well as they are not heard with good signals even in my area. I restarted listening in 1999 using good receiver' (T. Rajeesh, personal communication, July 27, 2002).

Jean Gabriel Manguy said that as a result of the changes with Radio Australia the station lost not just employees but many listeners. He said that

. . . for months afterwards we were receiving letters and people were telling us where have you been, where have you gone, why don't you talk to us anymore. That was a significant reaction from Asia in particular. 
You know you don't like us anymore, don't you want to talk to us anymore. From one day to another a whole audience disappeared. ( $A B C$ Online, 2002a).

As ethnic unrest grew in the South Pacific and Indonesia, the Australian Government began to backtrack on its decision. In 2001, Radio Australia received good news from the government when it announced the station would receive up to AUS\$9 million over three years for shortwave broadcasting to South-East Asia. The decision was prompted in part by pressure from the AsiaPacific region and continuing political turmoil in the region. The original decision to cut funding was made by Communications Minister Richard Alston following recommendations in the Mansfield Report. Australia's Foreign Minister, Alexander Downer, was never completely comfortable with the cuts to Radio Australia and was instrumental in restoring funding. In a joint statement Downer and Alston said, 'Recent events have highlighted the value of Australia's international broadcasting activities in conveying accurate news and information to the region as well as providing an Australian perspective' (Canberra restores station's funding, 2000: 9). The statement was a complete backdown by the Australian government. Since the earlier cut in funding, Radio Australia had not been heard west of Bali except by those able to access the station via the Internet. Now, by virtue of its strong signal, Radio Australia has established a prominent presence in the Asian and Pacific regions.

The irony of the situation is that when the cuts took place the Government sold off the Cox Peninsula transmitter site in Darwin, which was the main site for broadcasts into Asia. Once the funding was increased Radio Australia has had to lease time from that organization so as to use Radio Australia's former transmitters to broadcast back into Asia. In addition Radio Australia also uses $\mathrm{BBC}$ facilities in both Singapore and Taiwan to more effectively cover the region.

\section{Description and analysis}

\section{Government-foreign policy}

The Department of Foreign Affairs and Trade (DFAT) provides some funding for Radio Australia and is responsible for reaching out to other countries on behalf of Australia. If Radio Australia is a tool of foreign policy, then the policies of the DFAT directly affect the goals and operation of the station. The DFAT has five goals: 
- to enhance Australia's security.

- to contribute to growth in Australia's economy, employment and standard of living.

- to assist Australian travelers and Australians overseas.

- to strengthen global cooperation in ways that advance Australia's interests.

- to foster public understanding of Australia's foreign and trade policy and to project a positive image of Australia internationally (DFAT, 2002).

The department uses a number of means to achieve these goals, but it seems that, on the face of it, Radio Australia could be very useful in helping the department meet its objectives. However, there is more to it than just putting a station on the air. There must be clear objectives for the station and those objectives must line up with the foreign policy priorities of the country. Although the foreign policy priorities are stated, it is also clear that sometimes the priorities conflict. For example, Australian efforts to help East Timor achieve independence conflicted with its goal of strengthening relations with Indonesia.

Australia is a country that very much wants to be seen as an independent power in the Asia/Pacific region. It is a country that wants to carve out its own identity in the world system; an identity that leaves it free from dependency on other nations. The reality is that this is not easy, and Australia cannot survive in the current world system without dependence on the United States. The problem is that on the one hand Australia has strong ties with the United States, but it is also part of Asia (Lyon, 2001: 516). In an article for the Far Eastern Economic Review journalist Barry Hing writes, 'Australia must work out a position whereby it recognises its cultural differences and maintains its support for traditional allies, such as the U.S., and at the same time fit in comfortably in a region that may not always share such sympathies' (Hing, 2001: 30). Lyon (2001) writes,

In Colin Powell's confirmation speech before the US Senate, he stated that Washington would be looking to Australia for leadership and guidance on the difficult transition under way in Indonesia. While generous, this commitment only placed into sharper relief the existing tensions between Jakarta and Canberra [the respective capitals]. At least for the foreseeable future, Indonesian politics seem murky and unpredict- 
able, and the Indonesian-Australian relationship possesses little of the intimacy and warmth that characterized it only a few years ago (p. 517).

Indonesia is one of Australia's two largest partners in Asia, yet internal unrest and the situation in East Timor have meant that the relationship is not so sound (Lyon, 2001: 523).

As mentioned earlier, China is important to Australia, but Australia's relationship with the U.S. causes problems. The Australian Department of Foreign Affairs and Trade (DFAT, 2002) Annual Report 2000-2001 states, 'Bilateral trade with China increased significantly in 2000-2001, with total exports in 2000 rising 37 per cent over 1999 figures to almost A \$7 billion' (p. 7). In addition, conferences were scheduled with China to showcase Australian businesses. Meetings with high-level government officials were used to urge China to improve human rights issues and 'to ensure Australia's views on regional security issues were clearly understood by Chinese counterparts' (p. 7). Lyon (2001) writes that the crash of the US military plane on Hainan Island,

advertised how difficult Australia's position could become in instances of heightened tension between China and the United States. The accident occurred in a context where the new [U.S.] administration had already moved away from the previous administration's policy of treating China as a strategic partner. Australian foreign policy was left with no comfortable saddle point. Canberra's instinctive attraction to Washington's position was moderated by concerns about the level of anti-China rhetoric in Washington and a compelling wish to avoid a new bipolar contest between Australia's traditional ally and the fastest rising Asian great power. (p. 518)

Indonesia and China are very important to Australia, and therefore it is important for Radio Australia to have programming in Indonesian and Mandarin (also known as standard Chinese) in order to continue to build goodwill between Australia and the Indonesian and Chinese people. Hing (2001) points out that Australia needs to strengthen its relationship with Asia culturally as well as in other ways, but at the same time Asian countries need to be willing to accept Australia. He writes, 'Just as Australians have been urged to shun stereotypes about Asia, so too must Asians show a greater readiness to understand their 
neighbor and not to resort to clichés (p. 31). Radio Australia could well be a useful tool in promoting that type of understanding.

\section{Intermediary-Australian Broadcasting Corporation}

Looking at the relationship between the $\mathrm{ABC}$ and the Australian Government, and at documents such as the ABC Corporate plans, help us understand current and future plans for the $\mathrm{ABC}$ and Radio Australia. The legislation governing the $\mathrm{ABC}$ is the Australian Broadcasting Corporation Act 1983. As a result of this legislation, the Australian Broadcasting Commission became the Australian Broadcasting Corporation. Section 6 of the ABC Act details the Charter of the Australian Broadcasting Corporation (ABC Online, 2001b).

The 1983 Act states that the $\mathrm{ABC}$ has editorial independence from the Government and is accountable to the Parliament through its annual reports, corporate plans, and the appearance of $\mathrm{ABC}$ officials before Parliamentary committees. The Government department responsible for providing funding for the ABC is The Department of Communications Information Technology and the Arts (DCITA), which makes an appropriation to the ABC every year. This appropriation is based on a funding agreement negotiated every three years. The current funding cycle ends on 30 June 2003. Although Radio Australia is part of the ABC, it is actually funded by two Government departments, the Ministry of Foreign Affairs and Trade, which covers the programming in foreign languages, and the DCITA, which funds the cost of English language programming and satellite costs.

In addition to the Australian Broadcasting Corporation charter, Radio Australia is also governed by its own charter. The RA charter says the overarching goal of the Radio Australia is to ;foster international understanding of Australia and to reflect the nation's perspectives on the world ( $A B C$ Online, 2001b). In doing so, Radio Australia attempts to

- reflect the multicultural nature and socio-economic diversity of Australian society.

- encourage a free exchange of information, ideas and knowledge, acting as a credible and responsible window on the world.

- and foster an understanding of Australian attitudes and values while not excluding other attitudes and values. (p. 53)

Obviously such goals are lofty. The ABCEditorial Policies guide notes that, 'Translating goals into practical terms requires priorities to be set for regions, 
languages, target audiences, and broadcast content' (ABC Online, 2001b: 53). In terms of content, information services are listed as being at the center of Radio Australia's programming. In addition the broadcast of Australian regional and international news and current affairs are also a top priority. Finally, 'Radio Australia should also broadcast programmes which reflect Australia as a nation and encompasses the full spectrum of events and conditions-cultural, sociological, economic and political' (p. 53).

What is interesting about the identity of Radio Australia is that, because the station is so closely tied to Australia's public broadcasting service, Radio Australia itself is promoted as a public service broadcaster,

As part of the ABC, Radio Australia adheres to the highest standards of public broadcasting, including independent, unbiased and reliable news and information. Over 60 years RA has developed an enviable reputation as a trusted and friendly broadcaster. Whether we are reporting on the latest political crisis or providing educational information, you can depend on Radio Australia (ABC Online, 2003a).

Obviously, some of this is rhetoric, but the station, as part of $\mathrm{ABC}$, assumes the identity of the parent company. In doing so, it is able to draw on the services of the $\mathrm{ABC}$ and the reputation and goodwill that the $\mathrm{ABC}$ has within Australia, the Asia/Pacific region, and the world. It is an attempt to put a buffer between the station and its relationship with the Australian government and to solidify the claim that Radio Australia is neutral and independent and less an agent of propaganda by the Australian Government. As noted on Radio Australia's web site, 'by law and by convention neither the government nor parliament seeks to intervene in editorial decisions' (ABC Online, 2002c, p. 1). ${ }^{1}$ The priorities for Radio Australia are endorsed by the $\mathrm{ABC}$ Board, are subject to review and may be changed. So, for example, if Australia was to go to war, past history suggests the regional focus of the station and the languages used well may change. Critics also may point out, and rightly so, that even public service broadcasters with a reputation for integrity and quality programming are funded by the Government and so are still beholden to the hand that feeds them.

In March, 2003 the ABC was restructured and Radio Australia was moved from the radio division to a new international division which also includes the international TV service, ABC Asia Pacific TV. Radio Australia's general manager now reports directly to the $\mathrm{ABC}$ managing director. While this move 
may be seen as a way to stabilise Radio Australia and create a more solid identity, there are concerns that because the TV service carries advertising that Radio Australia will also be forced in that direction. That in turn will damage the service's editorial independence. There is also concern that the TV service will gain priority over radio (Radio Netherlands, 2003).

\section{Station output-target audience}

Radio Australia broadcasts in six languages: English, Indonesian, Mandarin, Vietnamese, Khmer (Cambodian), and Tok Pisin (Papua New Guinea). By comparison, the BBC World Service broadcasts in 43 languages and Voice of America 52. Radio Australia's target audience is people in the Asia-Pacific region and a major role of Radio Australia is to keep audiences in the Asia/ Pacific region and the wider global community informed about events and issues in Australia. This is achieved in part by broadcasting programmes from ABC Radio (ABC Online, 2003a).

Currently, Radio Australia's regional areas of focus are the South-West and Central Pacific, South-East Asia, North Asia, and South Asia. The Australian Broadcasting Corporation's Guide of Editorial Policies notes that 'English language broadcasts should be the flag-carrier of Radio Australia as English accurately expresses the culture of Australia and is the lingua franca of opinion leaders in the target countries' ( $A B C$ Online, 2001b: 53). This statement gives a significant clue to how the station is used: to promote Australia, Australian values, and Australia's view of the world. The priority is to reach those people who can affect change in their countries.

Following the national opinion leaders, the other two target audiences are, in order of priority, 'indigenous listeners with an interest in the world around them, and Australian expatriates' (ABC Online, 2001b: 53). The indigenous listeners will either have to speak English, or one of the other five languages to benefit from the programming. The assumption also seems to be that expatriates can gain information from 'home' from other sources but, if not, can always listen to Radio Australia. The languages Radio Australia uses shows that those regions and countries have special significance to the Australian Government.

Radio Australia uses many means to reach audiences in Asia and the Pacific. Radio Australia reaches into the French Pacific, with many local stations relaying portions of its programming. It also has a strong influence in Indonesia where local stations rebroadcast portions of its programming, and where it has 
an estimated weekly audience of almost 3 million people (Foreign radio stations, 1999).

However, the ability of the station to carry out the objectives and priorities of the Government depends on the funding from the Government through the Australian Broadcasting Corporation. Radio Australia is also constrained by the charter and policies established by the Australian Government. This in turn affects the output of the station and the way that the station is used.

This next section describes the programmes produced by Radio Australia and by the $\mathrm{ABC}$ including some program content and an explanation of the type of programming used by the station. The English service is the primary focus of analysis: the English language service broadcasts 7 days a week, 24 hours a day.

\section{English service \\ Programming}

Programming on Radio Australia is divided into five categories: news, current affairs and sport; political economic and social commentary; science and technology; music, arts, and culture; and education and knowledge. Among the categories, Current Affairs and News differ in terms of production value. Current Affairs programming is longer and contains in-depth coverage and analysis of national and international issues. News programming refers more to the bulletins aired every hour.

The Indigenous category is programming produced by Aboriginal broadcasters for a mainstream audience. It also contains programming examining indepth the many facets of Aboriginal culture.

Programmes in the Light Entertainment category may include comedies or dramas. Contemporary Life is programming that looks at current issues facing people in Australia.

\section{Radio National}

Radio Australia staff produce much of the News and Current Affairs programming aired on Radio Australia. However, the majority of programming aired over the English service of Radio Australia is produced by the ABC for broadcast over Radio National, a national terrestrial station heard in over 235 regional areas across Australia. Radio Australia merely rebroadcasts Radio

\section{National's programmes}

Radio National is branded as 'the ABC's specialist information and arts 
Content by genre percentage of total programming:

Current affairs

$25.4 \%$

News

$16.1 \%$

Music

$10.7 \%$

Sport

$8.4 \%$

Topical Radio

$5.6 \%$

Education

Light Entertainment

Science, Technology, Environment, Natural History

Contemporary Life

Arts \& Culture

Regional \& Rural

Religion \& Ethics

Law, Consumer Affairs \& Media

Health

Indigenous

Business \& Finance

$1.0 \%$

History

$0.7 \%$

Source: (ABC Online, 2001a).

network' (ABC Online, 2002a: 1) and its staff produces and airs over 65 different programmes. Before looking at those Radio National programmes aired specifically on Radio Australia, it is helpful to understand the philosophy that guides Radio National. Doing so makes it apparent why these programmes fit so easily with the mission of Radio Australia.

The philosophy can be best summed up in the following statements used by the ABC to describe Radio National:

Radio National provides a unique service giving Australians access to the world of social, cultural, political and economic ideas. This includes analysing, inquiring and provoking debate about 'why' and not simply 'what.'

Radio National aims to stimulate and entertain, increase curiosity and help ordinary, intelligent Australians make sense of an increasingly complex world. 
Radio National programs explore the capabilities of the radio medium itself and have the highest possible journalistic, ethical and production standards (ABC Online, 2002a: 1).

Obviously the target audience for Radio National programming is Australians. But, when the programming is retransmitted via Radio Australia, it fulfills the goal of exposing listeners overseas, both Australian and other nationalities, to the Australian culture, values, and ideals. The programming is not simply entertaining but educational and designed to give an Australian view on the region and the world. Having looked at the primary source of programming on Radio Australia, the next section examines the programmes that fall under the various categories, and the content of some of the programmes.

\title{
Radio Australia as a programme provider
}

Radio Australia serves two functions: that of a broadcaster providing programming direct to the listener, and that of a program provider providing programming for partner stations. The role as a program provider really developed from the cutbacks to the service that took place in 1997. Radio Australia's network manager Jean-Gabriel Manguy says that for many years shortwave broadcasting was a means to reach listeners in other countries from the safety of ones own shores. However, due to the changes beginning in 1997, Manguy notes,

\begin{abstract}
What we've achieved I suppose in the last five years is that, and we had no choice, is that we have left our shores ... and we have had to talk to various organizations to encourage them to relay Radio Australia. We've had to talk to other organizations to help us produce some content because, I mean, our resource base wasn't enough anymore (ABC Online, 2002d).
\end{abstract}

Manguy says that one of the biggest changes is that now instead of Radio Australia going to other stations to almost beg them to carry the programming, stations are now coming to Radio Australia requesting programming. Radio Australia provides almost 300 local and international radio stations with programming through what is known as 'Global Connections'. Individual stations or partner stations choose the programming they want from Radio Australia as well as the means of delivery that best suits the station's needs. Stations receive Radio Australia programming via satellite, mp3 files on the 
World Wide Web, shortwave, compact disc, or CD Rom. In addition, Radio Australia may also consider offering stations 'exclusive contractual arrangements, promotional and publicity support, co-productions, joint coverage of regional events, staff development exchanges and the provision of technical assistance' (ABC Online, 2002e: 8).

One new initiative that Radio Australia is involved in is partnerships with regional broadcasters. The Australian Broadcasting Corporation (ABC) and Radio Australia have entered into an agreement with Papua New Guinea's National Broadcasting Corporation (NBC). The agreement calls for journalists and producers from Radio Australia and the NBC to, in effect, change places and gain experience working in different cultures. However, it is not just about gaining experience as much as it is being able to offer a different point-of-view to the broadcasts. For example, the host of the NBC's morning show spent four weeks working with Radio Australia. He worked with both the English language and Pidgin (Papua New Guinean) services including contributing reports to the Pacific Beat programme and to Radio Australia's daily news broadcasts in Pidgin. Radio Australia's network manager, Jean-Gabriel Manguy, commented,

NBC journalists have contributed to several of our latest educational radio series about life in the Pacific. It is wonderful to be able to work more closely together as there is much we can learn from one another-and our listeners benefit too, from the richer, more diverse program content that results from closer interaction and cooperation between our two networks, our two nations (ABC Online, 2002b).

The partnership with regional broadcasters highlights an important role for Radio Australia. It is a role model for other broadcasters and stations in the AsiaPacific region. Because of the reputation its staff has, and because of its ties to the Australian Broadcasting Corporation, Radio Australia is a station other organisations want to emulate.

Six local stations in some of the largest urban areas in Indonesia carry news and current affairs programming from Radio Australia via satellite. Four of the stations in Medan, Jakarta, Bandung, and Sumedang, Indonesia, also carry a live weekly talkback show with broadcasters from Radio Australia's Indonesian service (ABC Online, 2002g). Similarly, Chinese stations that partner with Radio Australia also carry live talkback programming with Radio Australia's 
Chinese staff. The link into China has also necessitated that Radio Australia move in a new direction as a station; producing programming not for use on the station but specifically for air on stations in China. Manguy says, 'Our Chinese partners were telling us, you know, your English lessons are fine, your music programs are fine, but we want to respond to our audience who want to listen to programs in English, but in English that they will understand' ( $A B C$ Online, 2002d). So Radio Australia began producing such programming specifically for the Chinese stations.

One of the concerns of 'shortwave traditionalists' is that international broadcasters such as Radio Australia are moving away from, or neglecting, shortwave in favor of other means of delivery. Jean Gabriel Manguy notes that, particularly in Asia, they have not had any choice but to look at new ways of delivering the programming. He said,

recently, some of our technical people went to Indonesia to monitor our broadcasts and while shortwave broadcasts were clear in some provincial areas, in urban areas such as Jakarta the signal was just not getting through. So that's the reality of it. In the Pacific, as we know, the signal is there, the signal is strong. Now we don't have any figures on who listens to us. Papua New Guinea, certainly the indications are people certainly listen to us. I don't know that it's been one or the other until last year. Until last year we had basically no shortwave capacity to Asia. It's only in the last 12 months that, in English in particular, we've been back in Asia and only for seven hours a day, so it's not a matter of neglecting it was just not there (ABC Online, 2002d).

\section{Criticisms}

Not everyone is enamored with the use of Radio Australia by the Australian Government. Laisa Taga, editor-in-chief of the Islands Business International multimedia group and former editor of Fiji's Daily Post, is critical of Australia's seeming domination of Pacific Island media. She says, 'Turn on your radio in many Pacific Islands these days and you'll get news and views with an Australian accent and slant' (Pacific Islands Development Programme, 2002: 1). Taga says, 'The Aussies seem to have launched a massive drive to influence Pacific Islands people by providing news and views the Australian way through Radio Australia and Australian Television' (p. 1). Furthermore, Taga says Radio Australia is giving Pacific Island radio stations free satellite dishes so that they can rebroadcast Radio Australia programming. Taga says 
obviously such measures are good for Australia, but 'is it good for Pacific Island countries to have Australia having such an influence on what people see and hear?' (p. 1). While her perspective is relevant from a programmer's point-ofview, it would be hard to turn down the offer of a free satellite dish and free programming particularly as money is short for many small radio stations in the Pacific and professionally produced programming is hard to come by.

In 1997, the Mansfield Report noted that Radio Australia is not a 'core responsibility for Australia's national broadcasters' (Longreach to Phnom Penh, 2000: 4). Bob Mansfield said 'if there is inadequate resources and there is a choice between broadcasting to Phnom Penh and broadcasting to Longreach, then Longreach is going to win every time'. Therefore Mansfield felt justified in recommending cuts to Radio Australia as the 'local' audience should take priority.

This thought seems to be echoed by an editorial in The Australian which said 'what the ABC can and should be doing best is delivering balanced news and analysis - with an Australian perspective - to every corner of Australia. That is where it should focus its energies' (What does the ABC think it is doing?, 2003: 10). In other words the ABC should not concern itself with audiences overseas. As noted earlier much of Radio Australia's programming comes from Radio National. The Australian in its editorial; referred to Radio National as a network that 'appeals virtually exclusively to the values of ageing urban lefties, and as a result has shrunk to a mere asterisk in the ratings'. Obviously this is one papers view, but if the network is as irrelevant as the paper claims one must question whether its programming really is true representation of Australia's culture and values to those listening overseas.

\section{Comparison with Radio New Zealand International}

Radio Australia is not the only broadcaster with the Pacific region as a primary or secondary focus. Radio New Zealand International (RNZI) targets the Pacific region with a variety of programming similar to Radio Australia's. However, RNZI does so with nine full-time staff members compared to Radio Australia's 76 staff members (ABC Online, 2003e). Unlike Radio Australia, RNZI has no mandate to target Asia, although the service's broadcasts can be heard via shortwave in Asia and other parts of the world. Like Radio Australia, RNZI has suffered from lukewarm Government support and in 1997 came very close to being closed down altogether. ${ }^{2}$ In order to put Radio Australia's efforts into context it is necessary to look at the operation of RNZI.

96 PACIFIC JOURNALISM REVIEW 92003 
A major difference between RNZI and Radio Australia is the way both services are funded. RNZI's budget is NZ\$1.4 million with NZ\$1.2 million provided by the Ministry of Culture and Heritage. Up until January 2002 RNZI was funded by the Ministry of Foreign Affairs and Trade (Radio New Zealand Financial Report, 2002: 38). Although RNZI is under the auspices of Radio New Zealand it is not funded by Radio New Zealand. This may hold the key to the lack of Government support for RNZI. The mandate for the Ministry of Foreign Affairs and Trade is obviously to promote New Zealand's interests abroad, but is an international radio station committed to fair and objective reporting really a suitable vehicle for promoting trade and foreign affairs issues? The programming offered by RNZI definitely promotes New Zealand's culture and heritage and so its new association with this department makes more sense. However, Barry Corban, chairman of Radio New Zealand, has another suggestion. He believes it would be more beneficial for RNZI to be funded directly by Radio New Zealand in much the same way that Radio Australia is under the umbrella of the Australian Broadcasting Corporation and is also funded by it. Corban says, '[RNZI] operates under our organization, its people are our people and it is a key contributor to our programmes and to the proper discharge of our responsibilities' (Radio New Zealand Annual Report, 2002: 8).

RNZI broadcasts via shortwave for 105 hours per week with 28 of those hours being original news and programs provided by RNZI (Radio New Zealand Financial Report, 2002). The rest of the broadcasts are relayed from Radio New Zealand's National Radio in much the same way that Radio Australia uses programs from Radio National. The quality of RNZI originated broadcasts is measured by the degree these broadcasts are used by Pacific radio stations. There are 11 Pacific radio stations relaying RNZI news bulletins, and 'at least 80 per cent of RNZI news bulletins at the top of the hour are relayed by one or more Pacific radio stations' (Radio New Zealand Financial Report, 2002: 37). Unlike Radio Australia which provides streaming audio 24/7 via its website (www.abc.net.au/ra), RNZI only has a live feed of its breakfast show.

According to Radio New Zealand, the key services provided by RNZI are:

- its weather reports and 'cyclone watch', providing life-saving information to listeners in the Pacific Islands during the cyclone season

- its completely independent news service, providing authoritative and uncensored news bulletins

- its comprehensive coverage of South Pacific affairs, enabling Pacific 
Island nations to keep up with opinions and events in their neighbouring countries

- its wide range of Pacific Island news and programming, which it supplies to National Radio. (Radio New Zealand Online, 2003).

These goals are very similar to that of Radio Australia except RNZI appears to place more emphasis on weather related programming, particularly during the cyclone season. This effectiveness of this type of programming cannot be measured, but it may be among the most important functions of RNZI. Just as Australia supplies programming for the ABC, RNZI also provides National Radio with Pacific news bulletins and three Pacific feature packages each week for National Radio's evening programme (Radio New Zealand Annual Report, 2002:12).

Radio Australia and RNZI use shortwave to transmit programmes and programming from both services are re-broadcast by local stations throughout the Pacific. RNZI also broadcasts in several different languages, but these are restricted to newscasts. One other area where both Radio Australia and RNZI are similar is that they are engaged in training programmes in the Pacific. RNZI held a skills workshop in Vanuatu for Pacific women broadcasters and also provided training in election broadcasting for the Fijian Broadcasting Corporation (Radio New Zealand Annual Report, 2002:12). Radio Australia conducts training sessions with regional organisations such the Asia Pacific Institute for Broadcasting Development and the Pacific Media Initiative ( $A B C$ Online, 2003e). As mentioned earlier in this article it is also involved in staff exchanges with regional broadcasters ( $A B C$ Online, 2003f).

Both Radio Australia and Radio New Zealand International have suffered from a lack of Government support however, Radio Australia has had a lot of funding restored, while RNZI has struggled on with almost no funding at all compared to the task it is trying to achieve. Both stations complement each other. RNZI with its focus on the Pacific is able to provide news and information to stations throughout the region and also provide Pacific oriented programming to people in New Zealand. Radio Australia has a wider focus and provides stations in the Pacific with not just Pacific oriented news, but news and programming involving Asia. It is able to broaden the horizons of broadcasters and audiences in the region and show how Pacific issues fit within the greater Asia-Pacific arena. 


\section{Conclusion}

Radio Australia is a regional news and information source within the AsiaPacific region; it positions itself as 'Your Asia Pacific Network' ( $A B C$ Online, 2003a). Radio Australia is a source of information people can turn to to find out not just what is happening in Australia, but in their own country. In other words, it is a service to the people of the region provided by the Australian Government. The benefit of Radio Australia being so focused is that it can use its resources to effectively target in many different ways its desired audience. It does not have to stretch its funds trying to reach the world.

In looking at the foreign policy priorities of the Australian Government and the programming of Radio Australia it is clear that Radio Australia is being used to enhance the Australian Government's foreign policy in the Asia-Pacific region. The programming, and indeed the charter and other policies that govern the operation of the station, reflect Australia's culture and society. The station certainly serves as a symbolic presence for the Australian Government. The fact that Radio Australia's programming is rebroadcast on stations around the region gives Australia a presence in the minds of the listeners to those stations the country may not ordinarily have. In this sense Radio Australia serves an ambassadorial function for the Australian Government. However, Radio Australia is still very vulnerable to Government interference. Despite the fact that the service is not under Government control in terms of programming content, the Government still controls the money and without adequate finances the service cannot operate effectively.

The Australian Government is building and strengthening relationships with countries in the Asia-Pacific region. The languages Radio Australia uses, and the targeting of people in a position to influence others, is indicative of the Australian Government's desire to reach the Asia-Pacific region. While Australia maintains relations with countries in other parts of the world, it is a priority for it to cement its presence in the immediate region. Radio Australia's broadcasts play a vital role in helping the Australian Government build credibility in the Asia-Pacific region.

\section{Notes}

${ }^{1}$ The law mentioned is the Australian Broadcasting Corporation Act 1983.

${ }^{2}$ A more complete look at Radio New Zealand International by the author can be found on-line as part of the Pacific Radio Heritage Collection at radiodx.com/spdxr/RNZI2.htm 


\section{References}

Australian Broadcasting Corporation (ABC) Online. (2001a). Annual report. www.abc.net.au (Retrieved 29 January 2002).

ABC Online. (2001b). Guide to editorial policies. www.abc.net.au (Retrieved 29 January 2002).

ABC Online. (2002a). About us. www.abc.net.au/rn/mission.htm (Retrieved 13 June 2002,

ABC Online. (2002b). Australia-PNG partnership benefits radio broadcasters and listeners alike. www.abc.net.au/ra/about/stories/s561969.htm (Retrieved 10 January 2003).

ABC Online. (2002c). FAQs. www.abc.net.au/ra.about/faq.htm (Retrieved 6 June 2002).

ABC Online. (2002d). Feedback. www.abc.net.au/ra/feedback/brdcst5-7_july02.htm (Retrieved 5-7 July 200).

ABC Online. (2002e). Global connections: Partnership opportunities with Radio Australia. www.abc.net.au/ra/about/global.htm (Retrieved 17 November 200).

ABC Online. (2002f). Radio Australia Update September - October 2002. www.abc.net.au/ra/about/stories/s702009.htm (Retrieved 25 May 2003)

ABC Online. (2002g). Six partners deliver Radio Australia live to millions of Indonesians. www.abc.net.au/ra/about/stories/s494122.htm (Retrieved 6 June 2002).

ABC Online. (2003a). About Radio Australia. www.abc.net.au/ra/about/default.htm (Retrieved 17 January 2003).

ABC Online. (2003b). Broadcast schedule for April, 1952. www.abc.net.au/ra/gallery/ sched52.htm (Retrieved 15 January 2003)

ABCOnline. (2003c). Forces requests, 1967. www.abc.net.au/ra/gallery/wood67b.htm (Retrieved 15 January 2003).

Australian Department of Foreign Affairs and Trade. (2002). Annual Report 20002001. www.dfat.gov (Retrieved 28 January 2002).

Canberra restores station's funding. (2000, August 9). The Age, p. 9.

Department of Communications, Information Technology and the Arts. (1998).

Mansfield Report recommendations.

www.dca.gov.au/nsapi-graphics/?MIval=dca_dispdoc\&pathid=541 (Retrieved 6

February 2003).

Foreign radio stations remain favored alternative. (1999, April 25). The Jakarta Post.

Retrieved via Lexis-Nexis using the keyword: Radio Australia.

Hing, B. (2001). Howard goes forward. Far East Economic Review, 164(46), 30-31. Hodge, E. (1995). Radio wars: Truth, propaganda and the struggle for Radio Australia. Melbourne, Australia: Cambridge University Press.

Longreach to Phnom Penh. (2000, August 12). The Age, p. 4. 
Lyon, R. (2001). Issues in Australian foreign policy: January to June 2001. Australian Journal of Politics and History, 47(4), 516-530.

Pacific Islands Development Programme. (2002, May 7). Australia's national broadcaster accused of brainwashing. http://166.122.164.43/archive/2002/May/05-0922.htm (Retrieved 9 June 2002).

Radio Netherlands. (2003). Australia: Australian Broadcasting Corporation Restructures. www.rnw.nl/realradio/html/medianewsmar03.html (Retrieved 27 May 2003).

Radio New Zealand Annual Report. (2002). www.radionz.co.nz/au/f-au.htm (Retrieved 25 May 2003).

Radio New Zealand Limited Financial Report. (2002). www.radionz.co.nz/au/f-au.htm (Retrieved 25 May 2003).

Radio New Zealand Online. (2003). Overview. www.radionz.co.nz/au/f-au.htm (Retrieved 24 May 2003).

Thomas, A. (1980). Broadcast and be damned: The ABC's first two decades. Victoria, Australia: Melbourne University Press.

What does the ABC think it is doing? (2003, May 22). The Australian. p. 10

Dr Andrew M. Clark was born in Auckland and holds both New Zealand and American citizenship. He earned his PhD from the University of Florida in 2003. He is currently an assistant professor in the Department of Communication at the University of Texas at Arlington. 